\title{
PROCESSOS ALTERNATIVOS AO TRATAMENTO DOS RESÍDUOS SÓLIDOS GERADOS PELA INDÚSTRIA COUREIRO-CALÇADISTA
}

\section{E. ANDRIOLI e M. GUTTERRES}

Universidade Federal do Rio Grande do Sul, Departamento de Engenharia Química, Laboratório de Estudos em Couro e Meio Ambiente (LACOURO)

E-mail para contato: andrioli@enq.ufrgs.br e mariliz@enq.ufrgs.br

\begin{abstract}
RESUMO - A indústria coureiro-calçadista é responsável pela geração de uma grande quantidade de resíduos sólidos, que são destinados, na maioria das vezes, a aterros. Porém, esta seria a opção final para sua disposição, esgotadas todas as possibilidades para seu reaproveitamento. Neste cenário surgem, então, alternativas para o tratamento ou reaproveitamento destes resíduos. Entre elas, estão o co-processamento, onde os resíduos são utilizados como matéria-prima ou fonte de energia para substituir os recursos naturais e os combustíveis fósseis; a gaseificação, processo no qual é gerado gás combustível ou gás de síntese; e, no caso de resíduos sólidos orgânicos, a compostagem, objetivando a produção de um composto fertilizante. Neste trabalho será apresentado um estudo dos processos de co-processamento, gaseificação e compostagem, como alternativas ao tratamento dos resíduos sólidos gerados pela indústria coureiro-calçadista.
\end{abstract}

\section{INTRODUÇÃO}

Durante o processo de curtimento, as peles são transformadas em produtos estáveis ao ataque bacteriano. Assim o couro, produto final, é um material altamente resistente à degradação. Considerando-se que o ciclo de vida médio de couro curtido é entre 25 e 40 anos (Bertazzo et al., 2012), o acumulo deste material em aterros e a gestão da sua disposição implica um elevado custo econômico, bem como ambiental. Curtumes geram consideráveis quantidades de lodo, aparas, pelos e outros resíduos (Tahiri e De La Guardia, 2009), como consequência inerente da produção do couro. A valorização destes resíduos é caracterizada pela grande diversidade de técnicas empregadas ou recomendadas. Esta diversidade aumenta com a variedade de resíduos gerados. A tecnologia apropriada deve ser desenvolvida para promover a destinação adequada destes materiais.

A fabricação de calçados também é responsável pela geração de uma considerável quantidade de resíduos sólidos. Sendo estes, também de grande preocupação devido à diversidade de sua composição. Dentre os resíduos gerados por este setor, encontram-se: aparas de couro curtido, espumas, restos de materiais sintéticos, borracha, EVA, PU, tecidos, materiais a base de celulose e madeira, etc. A Figura 1 ilustra alguns exemplos de resíduos gerados na indústria coureiro-calçadista. 


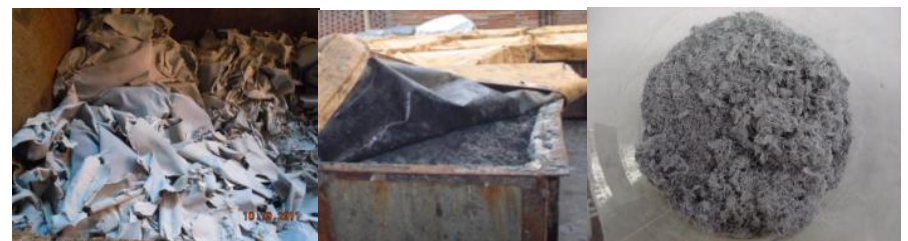

(a)

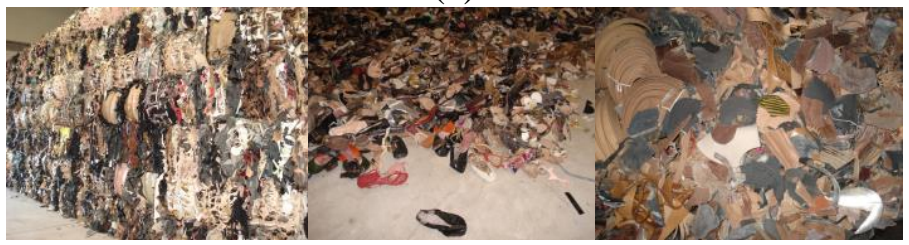

(b)

Figura 1-Exemplos de resíduos sólidos gerados na indústria coureiro-calçadista:

(a) resíduos de curtume, (b) resíduos de indústria calçadista.

Uma grande parcela destes resíduos é destinada a ARIPs (Aterro de Resíduos Industriais Perigosos). Em 2013, Kipper realizou um inventário sobre as condições e características de oito aterros de resíduos industriais perigosos localizados no Vale dos Sinos, região metropolitana de Porto Alegre/RS, e concluiu que os mesmos estavam de acordo com a norma brasileira ABNT NBR 10.157/87. Dentre os aterros entrevistados, três deles recebem resíduos tanto de curtumes, quanto de indústrias calçadistas, dispondo-os misturadamente. A Tabela 1 apresenta a relação dos resíduos atualmente recebidos e dispostos nestes aterros.

Tabela 1 - Relação de resíduos atualmente recebidos/destinados aos aterros.

\begin{tabular}{l|c|c|c}
\hline \multicolumn{1}{c|}{ Característica/ Aterros } & Aterro A & Aterro B & Aterro C \\
\hline$\cdot$ Farelo de rebaixadeira & & $\mathrm{x}$ & $\mathrm{x}$ \\
\hline$\cdot$ Lodo de ETE & $\mathrm{x}$ & $\mathrm{x}$ & $\mathrm{x}$ \\
\hline$\cdot$ Aparas de couro wet-blue & & $\mathrm{x}$ & $\mathrm{x}$ \\
\hline$\cdot$ Aparas de couro semi-acabado & & $\mathrm{x}$ & $\mathrm{x}$ \\
\hline$\cdot$ Aparas de corte (couro acabado) & $\mathrm{x}$ & $\mathrm{x}$ & $\mathrm{x}$ \\
\hline$\cdot$ Resíduos de fábrica de calçados & $\mathrm{x}$ & $\mathrm{x}$ & $\mathrm{x}$ \\
\hline Realiza aproveitamento de resíduos & $\operatorname{sim}$ & $\operatorname{sim}$ & $\operatorname{sim}$ \\
\hline
\end{tabular}

A disposição de resíduos curtidos e lodos em ARIPs é uma forma de destinação rápida e econômica, porém, não é uma solução permanente, pois os materiais ficam confinados, gerando um passivo ambiental a ser monitorado por muitos anos. A grande dificuldade dos aterros está na necessidade de construção de novas valas, pois os resíduos continuam sendo produzidos e a maior parte acaba sendo destinada para os aterros. Devido à grande quantidade de material encaminhado para disposição em ARIPs, a capacidade destes acaba sendo esgotada em curtos períodos, levando à construção de novos aterros ou valas. O desenvolvimento de tecnologias para diminuição do volume, ou alternativas para o reaproveitamento destes resíduos tornam-se prioridade, já que a construção de novas valas ou aterros é um processo caro, que envolve a licença de órgãos ambientais e leis, necessitando de um longo tempo até o início da disposição. 


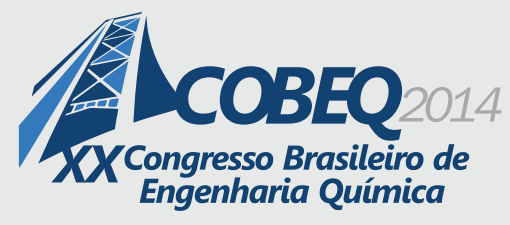

19 a 22 de outubro de 2014
Florianópolis/SC

Neste contexto, o tratamento térmico surge como uma alternativa para a destinação destes resíduos. Por meio do tratamento térmico, é possível produzir energia e garantir a redução do volume do material. Porém, esta prática gera cinzas que contêm quantidades elevadas de cromo. No entanto, pesquisas recentes concentram-se na busca de alternativas para o uso, reciclagem de metais e tratamento destas cinzas, como por exemplo, a produção de materiais refratários (Basegio et al., 2006), a produção de sulfato de cromo (Dettmer et al., 2010), e a utilização das cinzas como fonte de cromo para a produção de liga ferro-cromo de alto carbono (Alves et al., 2012).

Com relação aos resíduos sólidos orgânicos, os curtumes produzem quantidades substanciais de lodo e material não curtido, suscetíveis à fermentação em condições aeróbias. $\mathrm{O}$ lodo contém nitrogênio, cálcio, magnésio, fósforo, cromo trivalente e sódio. Assim, várias técnicas de compostagem podem ser utilizadas, dependendo da quantidade de lodo e resíduos a serem tratadas. A compostagem como um método para a gestão de resíduos sólidos de curtume é capaz de evitar muitos dos riscos ambientais e produzir um composto estável, apropriado para a fertilização do solo (Tahiri e De La Guardia, 2009; Amir et al., 2008).

O objetivo deste trabalho, então, é estudar alternativas para o tratamento dos resíduos sólidos gerados pela indústria coureiro-calçadista. Como alternativa aos resíduos orgânicos está a compostagem, técnica capaz de produzir material fertilizante ao solo. Com relação aos demais resíduos, está o tratamento térmico, como uma alternativa de reaproveitamento energético deste material. Sendo, neste caso, abordadas as tecnologias de co-processamento e gaseificação.

\section{TRATAMENTO TÉRMICO: CO-PROCESSAMENTO E GASEIFICAÇÃO}

Devido ao esgotamento dos combustíveis fósseis (petróleo, gás e carvão), e aos esforços para reduzir as emissões de $\mathrm{CO}_{2}$, a produção de combustíveis a partir de biomassa transformouse uma área de pesquisa em expansão. O co-processamento é o uso de resíduos como matéria prima e/ou como uma fonte de energia, para substituir os recursos naturais minerais e os combustíveis fósseis, em processos industriais, principalmente em indústrias de energia intensiva (produção de cimento e geração de energia). Entre os principais benefícios do co-processamento estão: a redução e o maior controle dos níveis de emissão de poluentes, substituição do combustível convencional em até $30 \%$, redução no consumo de energia, aumento do investimento na área ambiental, ganho de competitividade e a melhoria da imagem da empresa na comunidade (Sindicato Nacional da Indústria de Cimento, 2009; Lamas et al., 2013).

Alguns exemplos de resíduos geralmente co-processados são: óleo usado (inclusive lubrificante), solo e outros materiais contaminados com óleo (panos, serragem, vegetação), óleo solúvel e em emulsão, óleo sujo, graxa usada, filtro de óleo, resíduos de limpeza com solvente, escória de fundição de alumínio, ferro, aço e zinco, resíduos de minerais não-metálicos, soluções esgotadas de banho de tratamento superficial com cianeto; resíduos de pintura, emulsão asfáltica, solvente de parafina com tintas, borras de percloroetileno, misturas de resina e solvente, trietilenoglicol, pneus (Popovics, 1993; Carpio et al., 2008; Lamas et al., 2013). De acordo com 


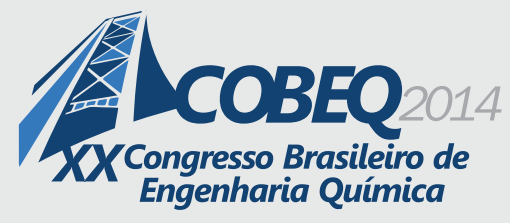

19 a 22 de outubro de 2014

Florianópolis/SC

os artigos $1^{\circ}$ e $2^{\circ}$ da Portaria n ${ }^{\circ} 16 / 2010$ da FEPAM (Fundação Estadual de Proteção Ambiental $\mathrm{RS}$ ), resíduos Classe I com características de inflamabilidade (solos, estopas e panos contaminados com óleo, por exemplo), não podem mais ser destinados a aterros, sugerindo-se pelo Art. $5^{\circ}$, desta mesma portaria, que sua destinação final seja realizada em unidades licenciadas de reprocessamento, recuperação, reciclagem, tratamento biológico, coprocessamento em fornos de clínquer ou de sistemas de tratamento térmico (incineração).

A gaseificação pode ser definida como a oxidação parcial de resíduos na presença de uma quantidade de oxidante menor do que a necessária para a combustão estequiométrica. Basicamente, uma parte do combustível é queimado para fornecer o calor necessário para gaseificar o resto. O resultado é um gás (combustível ou de síntese), contendo produtos não completamente oxidados, caracterizados por um valor calórico adequado para uso em equipamentos de outros processos. A gaseificação tem várias vantagens sobre os tradicionais processos de combustão de resíduos, principalmente devido à possibilidade de combinar o tipo de material de partida, as condições de operação e as características do reator para se obter um gás de síntese adequado para uso em diferentes aplicações (Arena, 2011).

A utilização de resíduos de couro (biomassa) para gerar energia torna-se interessante devido ao seu poder calorífico e às características da cinza gerada, a qual poderia ser utilizada em outros processos. Uma unidade semi-piloto $(350 \mathrm{kWth})$ foi projetada e construída para processar resíduos de couro, onde Godinho et al. (2007) avaliaram as emissões do gaseificador, e caracterizaram as cinzas e os gases de combustão. Foi possível concluir que: as condições operacionais aplicadas no processo forneceram um baixo grau de oxidação do cromo presente nos resíduos, a baixa concentração de CO nos gases de combustão indica uma alta eficiência de combustão do processo. Godinho et al. (2009) também realizaram a caracterização das emissões de dibenzo-p-dioxinas policloradas e dibenzofuranos (PCDD/F). A maioria dos PCDD/F foram encontrados na fase particulada ( $>95 \%)$, gás cloro não foi detectado, e a dependência entre a qualidade de combustão e a concentração de PCDD / F no gás de combustão foi comprovada.

Os resíduos coureiro-calçadistas representam uma fonte alternativa para a geração de energia. Verificando-se, assim, a possibilidade do tratamento térmico destes resíduos, desde que estes sejam devidamente caracterizados, e as condições operacionais do processo sejam devidamente avaliadas e utilizadas adequadamente para atingir o objetivo final: redução do volume de resíduo, geração de energia e minimização de passivos ambientais (minimização ou não geração de dioxinas e furanos, por exemplo), atendendo a legislação vigente.

Diversos materiais são utilizados na fabricação de calçados: laminados sintéticos em PVC, PU, EVA, mistos (PU e PVC), materiais têxteis. E, como consequência, resíduos destes materiais são gerados durante o processo produtivo. Alternativas para minimizar a geração destes resíduos são desenvolvidas através do ecodesign e da produção mais limpa com a fabricação de calçados ecológicos. O ecodesign tem como objetivo principal reduzir o impacto ambiental do produto em todas as principais fases do ciclo de vida de um produto (Reichert e Schmidt, 2006). No calçado, investir em pesquisa para melhorar o índice de recuperação e reutilização dos resíduos gerados durante a fabricação é um dos exemplos da aplicação do ecodesign. Serrano et al. (2007) 


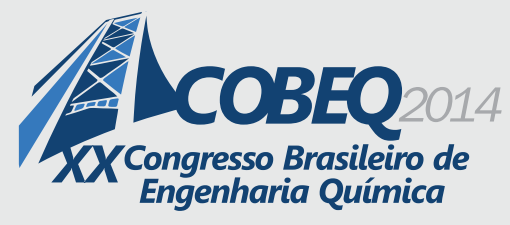

19 a 22 de outubro de 2014

Florianópolis/SC

realizaram um trabalho de obtenção do calçado ecológico de couro utilizando tecnologia limpa de produção. Foi utilizado couro curtido com aldeído glutárico e taninos vegetais, acabamento com substâncias classificadas como não perigosas, solado em borracha natural, adesivos sem solventes orgânicos. O contraforte, em material biodegradável, as espumas utilizadas foram de biolátex, e a embalagem foi de papel reciclado e biodegradável.

A Comissão da Comunidade Européia desenvolveu um selo ecológico que se trata de um dispositivo válido, reconhecido e único em toda União Européia (Weschenfelder, 2007), com capacidade de gerir e melhorar os impactos ambientais, cada vez mais um fator de competitividade. O selo é o mesmo para todos os grupos de produtos e para todos os países. No caso do calçado (Sánchez, 2007), o objetivo principal perseguido pelos critérios ecológicos é fomentar a limitação dos níveis de resíduos tóxicos, as emissões de compostos orgânicos voláteis e fomentar a fabricação de produtos mais duradouros. Com isso verifica-se que esforços estão sendo realizados para minimizar o impacto da indústria calçadista, porém muito ainda há muito que fazer com relação a não geração, reciclagem e/ou reaproveitamento dos resíduos calçadistas.

\section{COMPOSTAGEM}

A compostagem é um processo aeróbio em que microrganismos, termófilos e mesófilos, transformam a matéria orgânica e produzem um composto estabilizado e desinfectado. A sanitização de compostos geralmente está relacionada à fase termófila, quando as temperaturas chegam a $45-70^{\circ}$ C. Durante a fase mesófila (maturação), os compostos orgânicos restantes, mais recalcitrantes, são degradados mais lentamente, o que acarreta o desaparecimento de fitotoxicidade residual (Bhatia et al.,2013). O produto final não deve conter patogênicos ou ovos viáveis, e deve estar estável e adequado para utilização como um condicionador do solo. Fatores como: teor de oxigênio, umidade, composição, $\mathrm{pH}$ e temperatura, estão fortemente relacionados com as comunidades microbianas (Fornes et al., 2012).

O objetivo principal do processo é a redução do volume de resíduos sob a forma de composto orgânico, o que é viável dada a sua simplicidade tecnológica e aos baixos custos de investimento. Esta tecnologia apresenta-se como alternativa para a minimização dos efeitos do resíduo sólido no meio ambiente. O pelo é um resíduo recuperado na filtração do efluente de depilação e caleiro. Uma de suas principais características é o seu elevado teor de nitrogênio (12,2\%), um fator favorável para fins agrícolas. O pelo é um material orgânico biodegradável, que ao ser misturado com resíduos de pasto e poda, em determinada proporção, pode ser decomposto completamente, o que representa uma solução para o problema da gestão de resíduos, evitando seu envio a aterros. $\mathrm{O}$ composto orgânico à base de pelo vacum tem um possível mercado nas granjas, viveiros, jardins e cultivos orgânicos, com certas vantagens em relação a outros fertilizantes, por sua liberação mais lenta de nitrogênio (Careri e Morra, 2010). A aplicação de enzimas (Dettmer et al., 2013a) na etapa de depilação de peles bovinas (processo hair saving), vem sendo estudada com o objetivo de se obter pelos intactos ao final do processo. Entre as pesquisas realizadas estão a depilação co-enzimática (Souza et al., 2012), a depilação enzimática (Dettmer et al., 2013b), e a depilação enzimática-oxidativa (Andrioli e Gutterres, 2014). A recuperação dos pelos através destes processos, além de reduzir a carga orgânica nos 


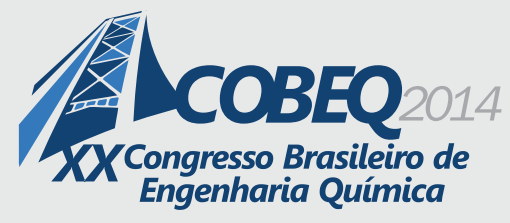

19 a 22 de outubro de 2014
Florianópolis/SC

efluentes, permite com que o pelo recuperado possa ser utilizado em outros processos, inclusive na compostagem.

Os principais resíduos sólidos proteicos gerados durante a fabricação do couro são provenientes da etapa de descarne. Os estudos de Ravindran e Sekaran (2010) relatam o tratamento destes resíduos para produção de um composto orgânico e seus efeitos sobre parâmetros fisiológicos de diferentes culturas. O resíduo foi hidrolisado utilizando Selenomonas ruminantium HM000123 e então misturado a esterco bovino e manta de folhas, para a produção de adubo orgânico compostado. A compostagem resultou em redução significativa do $\mathrm{pH}$, carbono orgânico total (COT) e razão C: N, aumento no teor de nitrogênio total Kjeldahl (NTK) após 49 dias. A germinação relativa de sementes, mostrou-se ser de $94 \%$ em tomate (Lycopersicon esculentum), $92 \%$ na grama verde (Vigna radiata), $86 \%$ em porongo (Lagenaria siceraria (Mol.)Standl), e $84 \%$ em pepino (Cucumis sativus L.). Os resultados indicam que a combinação de ambos, hidrólise e compostagem bacteriana, reduziu o tempo total necessário para a compostagem e produziu um produto composto enriquecido com nutrientes.

Vig et al. (2011) avaliaram o papel da minhoca na vermicompostagem do lodo de curtume. O lodo foi tóxico para as minhocas, por isso foi misturado com esterco bovino em diferentes proporções: 0:100 (T0), 10:90 (T10), 25:75 (T25), 50:50 (T50) e 75:25 (T75). A mortalidade mínima e maior acúmulo de população de minhocas foi na mistura T0. As quantidades de nitrogênio, sódio, fósforo, e o aumento do $\mathrm{pH}$, foram na faixa 7,3-66,6 \%, 16,90-70,58 \%, 8,57$44,8 \%$ e 2,8-13,65 \%, respectivamente. Potássio, carbono orgânico e a condutividade eléctrica diminuíram na faixa de 4,34-28,5\%, 7,54-22,35 \% e 32,35-53,12 \%, respectivamente. A relação C: $\mathrm{N}$ aumentou de $20,53 \%$ para $47,36 \%$ no produto final. Os metais de transição aumentaram significativamente a partir do valor inicial, mas dentro do limite permitido. O resultado indicou que a vermicompostagem com Eisenia fetida é capaz de transformar o lodo em um adubo rico em nutrientes em um curto período de tempo.

\section{CONSIDERAÇÕES FINAIS}

Neste trabalho fez-se um levantamento dos estudos realizados na área de destinação e tratamento final dos resíduos sólidos gerados pela indústria coureiro-calçadista. A compostagem mostra-se como a melhor alternativa de tratamento aos resíduos orgânicos, pois através desta técnica é possível evitar o envio deste material a aterros, evitando a formação de chorume nestes locais, e ainda produzir um composto orgânico, com características adequadas para uso na agricultura. Cabe aqui ressaltar que, no caso de resíduos contendo cromo o processo de compostagem e o composto produzido devem ser devidamente controlados e avaliados com relação à oxidação do $\mathrm{Cr}^{3+}$ a $\mathrm{Cr}^{6+}$, este último conhecido por sua toxicidade. $\mathrm{O}$ tratamento térmico, por sua vez, é uma alternativa aos demais resíduos. Fazendo-se uma separação prévia dos resíduos, reciclando ou reaproveitando o que for possível, o restante pode ser encaminhado para co-processamento ou gaseificação. A grande vantagem destas técnicas é o reaproveitamento energético do resíduo, evitando a queima de combustíveis fósseis, e promovendo a redução do volume de resíduo, sendo que, as cinzas geradas ainda podem ser reutilizadas para outros fins. 


\section{9 a 22 de outubro de 2014 \\ Florianópolis/SC}

Fica claro, assim, que há uma preocupação com relação ao tratamento/reaproveitamento dos resíduos da indústria coureiro-calçadista. Estudos estão sendo realizados, porém há muito que se estudar e se aprofundar com relação a estes resíduos. Deve-se, primeiramente, partir dos 3Rs da sustentabilidade (reduzir na fonte, reaproveitar e reciclar), e, a partir daí, encontrar alternativas de tratamento (tratamento térmico, compostagem), que permitam o processamento de todo resíduo, de tal forma que não seja mais necessário destinar estes a aterros, evitando assim diversos passivos ambientais, mas sempre respeitando a legislação e as normas ambientais vigentes.

\section{AGRADECIMENTOS}

Os autores agradecem ao CNPq (Edital Universal - MCTI/CNPq No14 /2013) e à FAPERGS (Edital 04/2012 - Programa PqG e Edital FAPERGS/CAPES 17/2012 - Programa de bolsas DTI, para centros e laboratórios multiusuários), pelo apoio financeiro a este projeto, e à CAPES pela concessão da bolsa de doutorado.

\section{REFERÊNCIAS}

ALVES, C. R.; BUZIN, P. J. W. K.; HECK, N. C.; SCHNEIDER, I, A. H. Utilization of ashes obtained from leather shaving incineration as a source of chromium for the production of HC-FeCr alloy. Mater. Eng., 29, p. 124-126, 2012.

AMIR, S.; BENLBOUKHT, F.; CANCIAN, N.; WINTERTON, P.; HAFIDI, M. Physico-chemical analysis of tannery solid waste and structural characterization of its isolated humic acids after composting. J. Hazard. Mater., v. 160, p. 448-455, 2008.

ANDRIOLI e GUTTERRES. Associated Use of Enzymes and Hydrogen Peroxide for Cowhide Hair Removal. JALCA, v. 109, p. 41-48, 2014.

ARENA, U. Gasification: An alternative solution for waste treatment with energy recovery. Waste Manage.,v. 31, p. 405-406, 2011.

ASSOCIAÇÃO BRASILEIRA DE NORMAS TÉCNICAS - ABNT. Aterros de resíduos perigosos Critérios para projeto, construção e operação: NBR 10157:1987. 13 pg., Rio de Janeiro, 1987.

BASEGIO, T., HAAS, C., POKORNY, A., BERNARDES, A.M., BERGMANN, C.P. Production of materials with alumina and ashes from incineration of chromium tanned leather shavings: environmental and technical aspects. J. Hazard. Mater, v. B137, p.1156-1164, 2006.

BERTAZZO, M.; POVEDA, D.; ALBERT, A.; GARCIA-GRAS. N.; SEGARRA-ORERO, V.; MARTÍNEZ-SANCHEZ, M. A. System for biodegradability evaluation on leather used in footwear industry. Journal of Asociación Química Española de la Industria del Cuero (AQIC), v. 63, p. 61-69, 2012.

BHATIA, A.; MADAN, S.; SAHOO, J.; ALI, M.; PATHANIA, R.; KAZMI, A. A. Diversity of bacterial isolates during full scale rotary drum composting. Waste Manage., 33, p. 595-1601, 2013.

CARERI, M. J. R. e MORRA, R. A. L. Geração de composto orgânico a partir de pelo vacum. Revista do Couro, v. 212, p. 34-41, 2010.

CARPIO, R.C.; JUNIOR F. S.; COELHO, L.S.; SILVA, R.J. Alternative fuels mixture in cement industry kilns employing particle swarm optimization algorithm. J. Braz. Soc. Mech. Sci., vol.30, p. 335-340, 2008.

DETTMER, A., NUNES, K.G.P., GUTTERRES, M., MARCÍLIO, N.R., 2010. Production of basic chromium sulfate by using recovered chromium from ashes of thermally treated leather. J. Hazard. 


\section{9 a 22 de outubro de 2014 \\ Florianópolis/SC}

Mater, v. 176, p. 710-714, 2010.

DETTMER, A.; ANJOS, P. S.; GUTTERRES, M. Special Review Paper: Enzymes in the Leather Industry. JALCA, v. 108, p. 146-158, 2013a.

DETTMER, A.; CAVALLI, E.; AYUB, M. A. Z.; GUTTERRES, M. Environmentally friendly hide unhairing enzymatic hide processing for the replacement of sodium sulfide and deliming. J. Clean. Prod., v. 47, p.11-18, 2013b.

FORNES, F.; HERNÁNDEZ, D. M.; DE LA FUENTE, R.G.; ABAD, M.; BELDA, R. M. Composting versus vermicomposting: A comparative study of organic matter evolution through straight and combined processes, Bioresource Technol, v. 118, p. 296-305, 2012.

GODINHO, M., MARCILIO, N.R., VILELA, A.C., MASOTTI, L., MARTILINS, C.B. Gasification and combustion of the footwear leather wastes. JALCA, v. 102, p. 182-190, 2007.

GODINHO, M.; MARCILIO, N. R.; MASOTTI, L.; MARTINS, C. B.; RITTER, D. E.; WENZEL, B. M. Formation of PCDD and PCDF in the thermal treatment of footwear leather wastes. J. Hazard. Mater, v. 67, p. 1100-1105, 2009.

KIPPER, E. Tratamento Enzimático e Produção de Biogás por Resíduos Sólidos de Curtume. Dissertação de Mestrado PPGEQ - UFRGS, 2013.

LAMAS, W. Q.; PALAU, J. C. F.; CAMARGO, J.R. Waste materials co-processing in cement industry: Ecological efficiency of waste reuse. Renew Sust Energ Rev, v. 19, p. 200-207, 2013.

POPOVICS, S. Portland cement-fly ash-silica fume systems in concrete. Adv Cem Based Mater, vol 1 (2), p. 83-91, 1993.

PORTARIA N 016/2010, DE 20 DE ABRIL DE 2010. Fundação Estadual de Proteção Ambiental FEPAM-RS.

RAVINDRAN, B. e SEKARAN, G. Bacterial composting of animal fleshing generated from tannery industries. Waste Manage., v. 30, p. 2622-2630, 2010.

REICHERT, I. K. e SCHMIDT, M.R. Dossiê Técnico: Aplicação do conceito de Ecodesign em calçados. Centro Tecnológico do Calçado, SENAI-RS, 2006.

SÁNCHEZ, M. A. M. Ecoetiqueta é um importante apelo de venda na Europa. Tecnicouro, v. 28, n², p. 36-40, 2007.

SERRANO, C. L. R.; REICHERT, I. K; SCHMIDT, M. Uso de tecnologia limpa na indústria de calçados. In: $1^{\circ}$ Forum Internacional de Resíduos Sólidos, 2007, Porto Alegre. Anais do $1^{\circ}$ Fórum Internacional de Resíduos Sólidos, 2007.

SINDICATO NACIONAL DA INDÚSTRIA DE CIMENTO. Relatório Anual 2009. Disponível em www.snic.org.br/pdf/relat2009-10web.pdf (acesso em 29/03/2014).

SOUZA, F. R.; BENVENUTI, J.; SILVA, M. C.; GUTTERRES, M. Análise de Efluentes de Processos de Depilação/ Caleiro com Diferentes Formulações. XIX Congresso Brasileiro de Engenharia Química, Búzios, R.J., 2012.

TAHIRI, S. e DE LA GUARDIA, M. Treatment and valorization of leather industry solid wastes: a review. JALCA, v. 104, p. $52-67,2009$.

VIG, A. P.; SINGH, J.; WANI,S. H.; DHALIWAL, S. S. Vermicomposting of tannery sludge mixed with cattle dung into valuable manure using earthworm Eisenia fetida (Savigny). Bioresource Technol, v. 102, p. 7941-7945, 2011.

WESCHENFELDER, V. F. Consciência ecológica é o futuro da moda. Tecnicouro, v. 28, n³, p. 64-65, 2007. 